\title{
Lexicografia Pedagógica: um relato da experiência do uso de dicionários para ensinar italiano a um grupo da 'melhor idade'
}

\author{
Pedagogical Lexicography: a report of an experience about dictionary use for \\ teaching Italian language to elderly students
}

Fábio Henrique de Carvalho Bertonha*

RESUMO: Este artigo visa relatar a experiência de seu autor ao ministrar a língua italiana para estudantes da terceira idade. Sabe-se que o envelhecimento é um processo natural na vida humana, porém, há uma tendência à exclusão dos idosos. Diante dessa questão, algumas instituições educacionais passaram a oferecer cursos voltados para esse público a fim de reinserir a população idosa na sociedade da qual faz parte. Em Barretos, o UNIFEB é uma universidade que oferece cursos de línguas estrangeiras para esses estudantes mais velhos. Neste artigo, há o relato do autor que ministra, voluntariamente, língua italiana para alunos idosos do projeto de extensão chamado UAMI. Objetiva-se compartilhar as atividades experienciadas, algumas características específicas, expectativas e interesses desse grupo consoante a estudos contemporâneos.

PALAVRAS-CHAVE: Lexicografia. Ensino. Aprendizagem. Língua italiana. Idoso.

\begin{abstract}
This paper aims at relating an author's experience in teaching elderly students in Italian language. It is known that the aging is a natural process on human life, however, there is a tendency for excluding older people. Therefore, some educational institutions decided to offer courses focused on this target group in order to reintegrate the elderly population in the society which is part. In Barretos, UNIFEB is a university which offers foreign language courses to these older students. On this paper, there is an author's report, who voluntarily teaches Italian language to elderly students as part of an extension project called UAMI. It aims to share experienced activities, some specific characteristics, expectations, and interests of this group according to current studies.
\end{abstract}

KEYWORDS: Lexicography. Teaching. Learning. Italian language. Elderly.

\footnotetext{
* Doutorando em Lexicologia e Lexicografia pelo Programa de Pós-Graduação em Estudos Linguísticos, UNESP-IBILCE, bertonha.tradutor@hotmail.com.
} 


\section{Introdução}

A cada dia, é notório que o mercado de trabalho está mais exigente, por conseguinte, há um crescimento do ensino de línguas estrangeiras no Brasil, notadamente observado pelo aumento do número de escolas de idiomas em todo o país. Se por um lado, esses centros educacionais servem àqueles que duvidam e criticam a eficácia do ensino nas escolas públicas e/ou privadas ou que não conseguiram acesso por meio de vestibular; por outro lado, muitos profissionais, graduados ou não procuram esses locais de ensino para conseguirem se manter em um mercado de trabalho cada vez mais especializado e competitivo. Almeida Filho (1993, p. 17) aponta que, com isso, não apenas o público tradicional das instituições de $1^{\circ}, 2^{\circ}$ e $3^{o}$ graus, mas também há uma imensa demanda por cursos oferecidos em escolas de idiomas visando ao atendimento dessa variedade de indivíduos, isto é, tanto em relação à faixa etária (de crianças a adultos) quanto às mais diversas ocupações (estudantes, professores, executivos, entre outros).

No entanto, até bem pouco tempo, um segmento da sociedade vinha sendo ignorado por esses espaços de ensino: os adultos mais velhos que se encontram na ponta da idade madura, ou seja, os adultos da terceira idade. Hodiernamente, presencia-se que várias instituições de ensino têm se mostrado avançadas em iniciativas de superação do estigma sofrido pela camada mais idosa da população. $\mathrm{O}$ Centro Universitário da Fundação Educacional de Barretos (UNIFEB), por exemplo, vem desenvolvendo um trabalho pioneiro em uma cidade do interior do estado de São Paulo a partir da fundação da 'UNIFEB Aberta à Melhor Idade (UAMI)', desde 2009. Hoje, dezenas de adultos com mais de 45 anos já frequentaram e têm frequentado os mais diferentes cursos oferecidos pelo UNIFEB.

É inserido nesse contexto de mudanças de perspectivas e de avanços na concepção do envelhecimento que várias universidades, assim como o UNIFEB, têm dado oportunidades de estudos ao público idoso, promovendo sua reinserção social. 
Há um contínuo interesse pelos cursos de línguas estrangeiras, pois, conforme afirma Pereira (2005, p. 68), “o aprendizado de uma língua estrangeira propicia a esse idoso buscar soluções para se inserir na sociedade pela ferramenta da educação", bem como o exercício mental, propiciado no processo de ensino-aprendizagem, auxilia no retardo da senescência (p. 27).

Este trabalho pretende relatar momentos vivenciados durante as aulas de língua estrangeira (italiano) ministradas, voluntariamente, pelo autor deste artigo para alunos idosos desde 2016 na UAMI. De início, é destacado o perfil particular que caracteriza um aluno idoso a fim de ressaltar o quão relevante é ter um olhar específico ao lecionar para esse público. Na sequência, são apontados os estudos de alguns autores que dizem respeito à área com o intuito de se pensar no processo de ensinoaprendizagem de línguas. Além disso, pretende-se destacar a importância da cultura e também como o dicionário pode contribuir nesse processo. Não se almeja estabelecer regras para ensinar a população, mas tão somente compartilhar experiências de ensino em sala de aula que despertaram ainda mais interesse pela Itália, sua língua e cultura.

\section{Terceira Idade: considerações e comportamentos}

O gerontologista francês Huet (DEBRAY, 1961, on-line) cunhou o termo 'terceira idade', buscando definir a fase mais madura da vida do ser humano que se inicia próximo à aposentadoria. Acredita-se que tenha sido adotado em nosso país devido ao fato de que os primeiros gerontologistas tenham tido sua formação na França. No entanto, esse período da vida tem sido bastante discutido por psicólogos, geriatras, gerontologistas, educadores e sociólogos. A Organização Mundial de Saúde (OMS) vem considerando a idade de 60 anos como o início da terceira idade, porém, enquanto uma parcela dos geriatras concorda com esse limite, outra parte considera como pertencentes a essa faixa etária somente adultos com mais de 70 anos. De modo geral, 
as instituições educacionais consideram como pertencentes à terceira idade aqueles adultos que tenham acima de 45 anos (HADDAD, 1986, p. 25).

Seja como for, aquilo que importa é destacar que a denominação dessa fase comumente está relacionada ao envelhecimento, logo, é esperado que haja divergências entre os profissionais de diversas áreas acerca do início da terceira idade. Afinal, de uma perspectiva biológica, a velhice corresponde à fase da vida na qual traços de senilidade (prejuízo de sentidos como visual e auditivo) tornam-se mais evidentes; já de uma perspectiva econômica, o envelhecimento está ligado à fase improdutiva da vida humana (FRIEDAN, 1993, p. 549), isto é, após a aposentadoria.

Haddad (1986, p. 10) constata que

em função do novo padrão demográfico em formação, emerge um significativo investimento na denominada problemática da velhice, consubstanciado em propostas para a melhoria da qualidade de vida do fim da vida, propostas estas amparadas na ideia de que é preciso assistir aos idosos, enquanto segmento esquecido da sociedade.

Levando em consideração quais seriam as possíveis perdas e quais os possíveis ganhos, poderiam ser traçadas algumas estratégias para que a sociedade se tornasse mais apta a desenvolver atividades adequadamente direcionadas à terceira idade, inclusive na área de ensino de línguas.

Em termos de legalidade, de interesse e de pesquisa com relação a esse segmento da população, surge no contexto brasileiro, em outubro de 2003, o Estatuto do Idoso. Referente a essa parcela, conforme dados do Instituto Brasileiro de Geografia e Estatística (IBGE, 2004), nota-se uma nítida transformação na estrutura da pirâmide populacional do país, assim como sua evolução de 1980 a 2050, quanto ao número de indivíduos demonstrado pelos dados no Gráfico 1, a seguir: 
Gráfico 1: Pirâmide populacional de 80 anos ou mais, de 1980 a 2050.

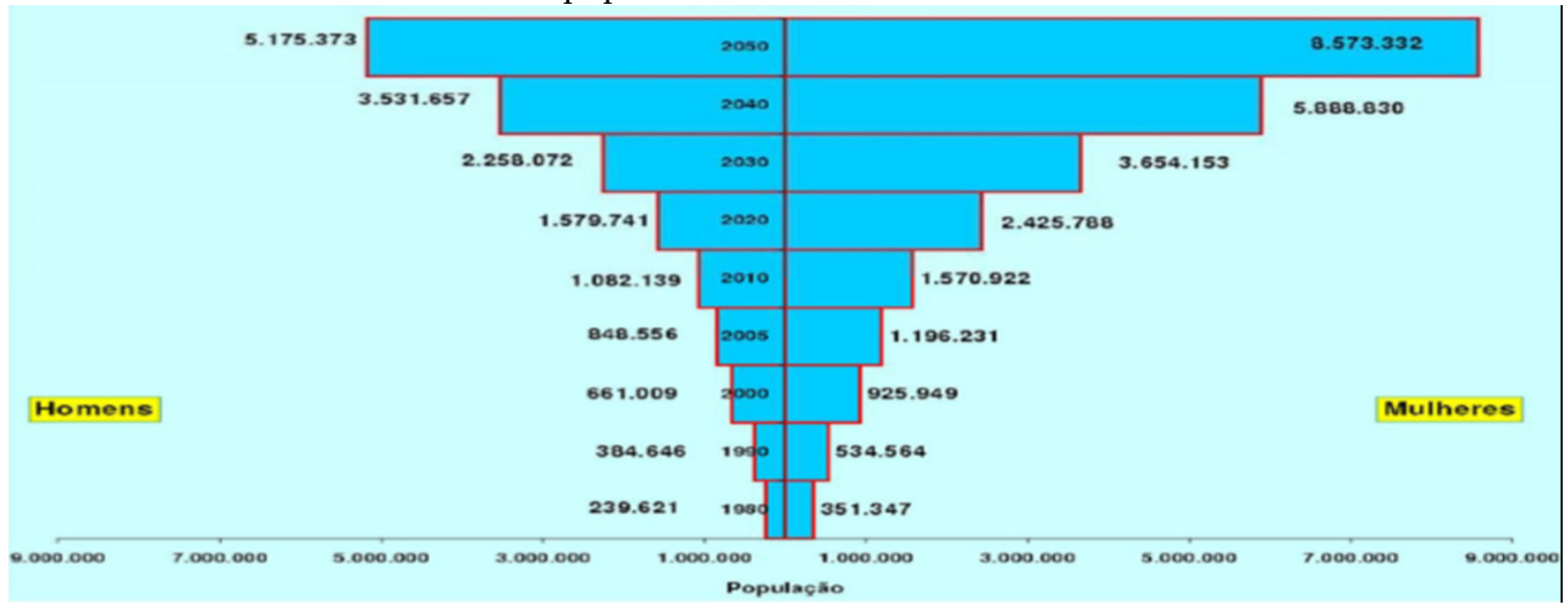

Fonte: IBGE (2004, p. 68).

Nesse primeiro gráfico, encontra-se contrastada a quantidade de idosos de 80 anos ou mais de idade, divididos por sexo e por décadas, iniciando-se em 1980 e projetando-se até 2050. É possível notar que a quantidade de homens idosos aumenta em 21 vezes, enquanto que o número de idosas, sempre maior do que o de homens, aumenta em 24 vezes.

Ao se focalizar a década de 1980, tem-se a seguinte constatação:

Gráfico 2: Pirâmide etária absoluta de 1980.

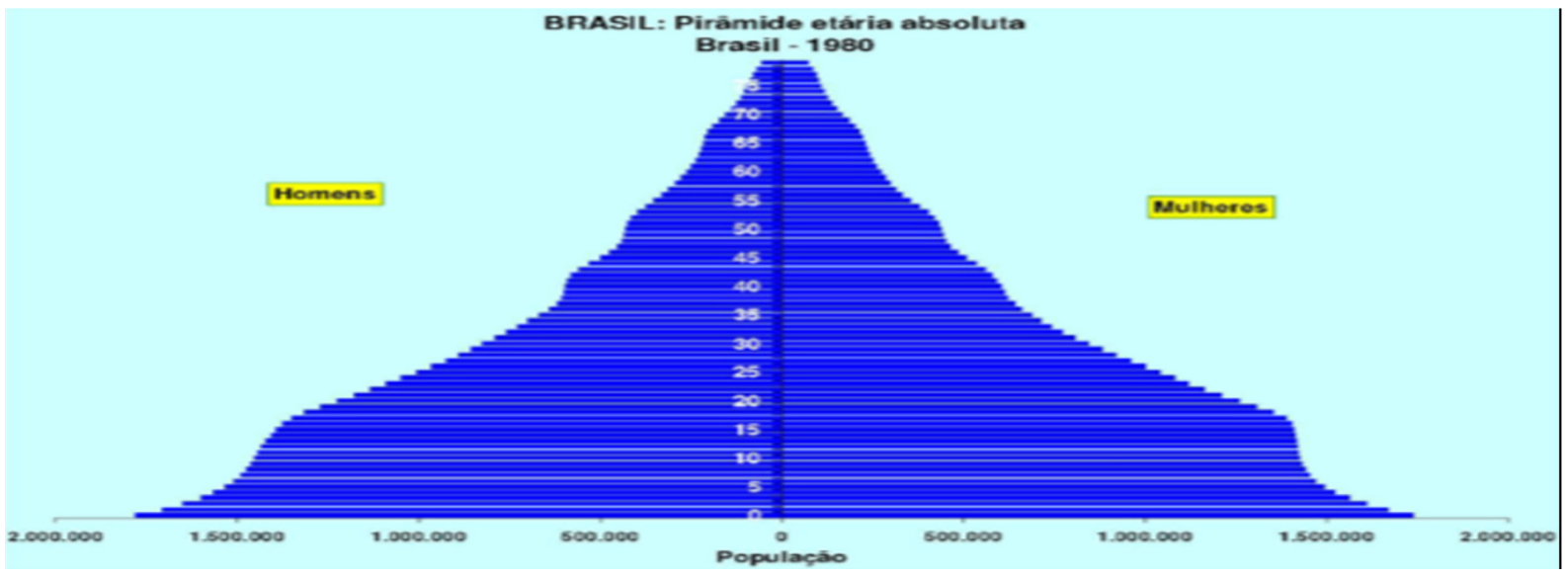

Fonte: IBGE (2004, p. 69). 
Notoriamente, a pirâmide populacional apresenta um número bem reduzido de idosos (no topo), sobretudo se comparado à quantidade de pessoas mais jovens (base), demonstrando uma menor expectativa de vida e uma maior taxa de natalidade.

Segundo a perspectiva prevista para 2050, o gráfico populacional irá apresentar a seguinte mudança:

Gráfico 3: Pirâmide etária absoluta de 2050.

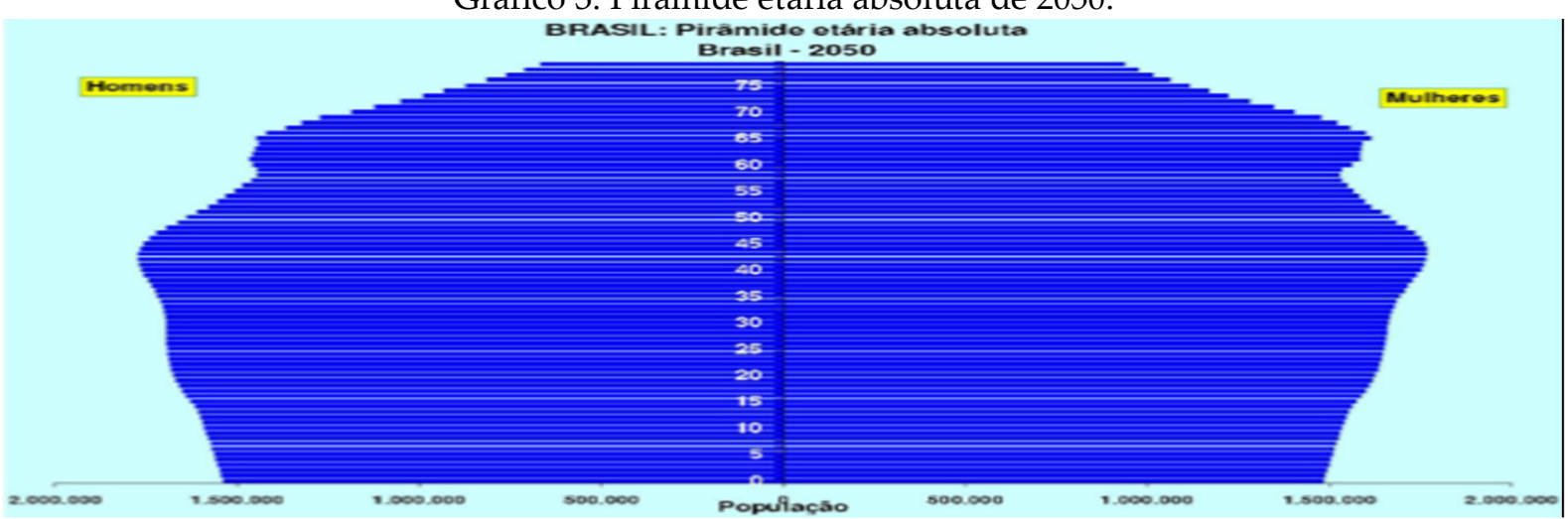

Fonte: IBGE (2004, p. 72).

Essa alteração, calculada pelo IBGE, demonstra uma diminuição na taxa de natalidade infantil, mas principalmente um aumento na expectativa de vida do brasileiro.

A partir disso, constata-se que essa modificação no volume populacional do Brasil afeta todos os setores, inclusive, o setor educacional e, por consequência, o processo de ensino-aprendizagem de línguas estrangeiras. Os artigos de 20 a 25, Título II, Capítulo 5 do Estatuto do Idoso dispõem sobre o direito à educação, cultura, esporte e lazer. Resumindo-os, pode-se verificar que muitos dos serviços dessas áreas precisam ser adaptados para que se respeite a condição da idade.

Com efeito, é necessário que o material didático, o currículo e as metodologias sejam adaptadas, logo, deve haver cursos especiais com conteúdo propício relativo à comunicação e aos avanços tecnológicos a fim de integrar a população idosa à vida contemporânea. 


\section{O idoso e o processo de ensino-aprendizagem}

Há uma tendência, conforme Hall (2011, p. 116), de se ministrar aulas de língua estrangeira ignorando as particularidades individuais de cada aluno (como por exemplo, idade, gênero, tempo e motivação para estudar, nível de língua materna, identidade social e étnica, dentre outras), logo, a incompreensão ou o desinteresse em observá-las pode implicar no insucesso da aprendizagem dos educandos. Por outro lado, um olhar mais atencioso para essas características - inerentes a cada pessoa poderia contribuir para o trabalho docente, visto que cada professor irá desenvolver um modo de lecionar conforme seu entendimento e arcabouço teórico sobre a aquisição de linguagem. Não se pode negligenciar o fato de que cada aluno é um ser sócio-histórico, portanto, é fruto de uma realidade específica que moldará sua constituição identitária e, consequentemente, seu olhar para as línguas estrangeiras.

No que diz respeito à fase da vida para se estudar uma língua estrangeira, notase que há pontos de vista divergentes, pois, no decorrer de anos de ensino, vários professores vinham defendendo e acreditando na ideia de que quanto mais jovem fosse o estudante, maiores seriam suas chances de obter um resultado positivo no processo de ensino-aprendizagem. No entanto, sob esse ângulo, a neurociência tem se mostrado contrária a tal argumentação dado que estudos realizados por gerontologistas vêm demonstrando que também há conexões nervosas que surgem com o avançar da idade (PEREIRA, 2005, p. 30).

Ainda é importante ressaltar que as relações semântico-pragmáticas, bem como a facilidade para a aquisição vocabular, ocorrem graças ao desenvolvimento das células neurais com o decorrer dos anos de cada indivíduo (SCHLEPPEGRELL, 1987, p. 144), pois um adulto é capaz de continuar realizando essas associações.

É preciso ter um olhar ainda mais perspicaz porque o aluno idoso faz parte de uma parcela educacional que não apenas deseja preencher o tempo livre, mas principalmente busca sua reinserção social. Portanto, é necessária uma abordagem 
diferenciada por parte do professor junto a esse público para que se consiga haver êxito no processo de ensino-aprendizagem. Com efeito, o ensino de uma nova língua faz com que o aluno entre em contato com uma nova cultura, levando-o a reconstruir seus próprios valores socioculturais.

Desse modo, uma das motivações para estimular esse aluno idoso pode ser por meio da influência do contexto sociocultural da língua estrangeira estudada. Schütz (2014, on-line) afirma que a motivação pode ser ativada por fatores internos e externos, mas sempre parte de um desejo de busca por satisfazer as necessidades pessoais, reforçando, assim, que aprender línguas é um processo ativo, no qual a motivação do aluno é a peça-chave desse processo.

Lieb (1999 apud VINTRÓ DE DEUS, 2007, p. 30-31) destacou alguns possíveis fatores que podem ser tidos como motivadores durante o processo de ensinoaprendizagem, a saber: (i) relações sociais, pois os alunos podem estar motivados para retomar ou aumentar o contato social; (ii) expectativas externas, dado que alguns alunos também pensam em retornar ao mercado de trabalho; (iii) expectativas internas, visto que existe o desejo de desenvolvimento pessoal; (iv) escape/estimulação, pois alguns alunos também veem a aula de língua como um momento de relaxamento mental depois de um dia de trabalho árduo.

Em se tratando da sala de aula, pode-se dizer que a motivação provenha, principalmente, dos fatores internos e externos anteriormente mencionados. No entanto, ainda vale a pena detalhar que, quanto a essas expectativas internas, há a sensação de progresso do aluno, sua aptidão para a língua, a ansiedade pessoal etc., enquanto que às externas, há a interação com outros alunos, os elogios, a forma de correção proposta diante da classe etc. Portanto, é fundamental a atenção do professor a fim de identificar possíveis dificuldades enfrentadas por cada aluno idoso, bem como integrá-lo à cultura da língua estudada, particularmente quanto ao caso do curso tratado aqui: língua italiana. Assim, é essencial que os alunos compreendam as 
questões culturais que dizem respeito aos italianos a fim de entender, por exemplo, a formação de seus estereótipos.

O docente precisa estar atento quanto à concepção de língua e do processo de ensino-aprendizagem que desenvolve em sala, visto que influenciará diretamente no aprendizado de seus alunos. Não se pode desconsiderar que esse público estudantil já passou por várias experiências em termos do processo de ensino-aprendizagem, logo, essa vivência influenciará a construção do conhecimento de uma nova língua. Com isso, as práticas de correção, de formulação e execução de exercícios, de uso de materiais, como por exemplo, o dicionário, de tradução, enfim, devem ser repensadas para esse público mais velho.

\section{Dicionários: materiais úteis para o aprimoramento da leitura e aquisição do léxico}

O dicionário, assim como a própria escrita, trazem consigo uma história. Poderiam ser lembradas as longas listas de palavras escritas, ainda a certa época, em papiro, ou mesmo nas várias listas de palavras que um aprendiz de língua estrangeira precisaria (ou deveria) formular a fim de aprender o grego ou latim clássico. No entanto, o dicionário não pode mais ser visto somente como mera listagem tal como era na escola clássica, grega e latina, mas sim como fonte de informações sóciohistórico-culturais registradas por um profissional da língua.

Biderman (1984, p. 27) pontua com relação à importância desse uso em sala de aula e atesta que o dicionário

serve como instrumento para orientar os seus consulentes sobre os significados e os usos das palavras, e para que eles possam expressar suas ideias e sentimentos com maior precisão e propriedade possíveis, utilizando o tesouro léxico que a língua põe à disposição dos falantes do idioma. 
Há uma gama de possibilidades para que o professor possa fazer uso dos dicionários como instrumentos de ensino em sala de aula, porém, raras são as aulas voltadas especificamente para o uso dessa ferramenta. Os docentes poderiam se questionar sobre o porquê de não estudar o dicionário da mesma forma e com o mesmo ímpeto que se dedicam a outros gêneros textuais. Levando esse aspecto em consideração, a proposta no curso 'Língua e Cultura Italianas' - curso oferecido pela UAMI - procura aproximar os alunos idosos do dicionário.

Não apenas nas aulas de línguas estrangeiras, mas sim professores de outras disciplinas precisam compreender que o dicionário pode ser tomado como um gênero textual do qual o aluno necessitará para melhor desenvoltura nos demais gêneros.

Embora na prática cotidiana em sala de aula, muitos tomem o dicionário como material de apoio ou fonte de consulta, desconsiderando-o como instrumento de aprendizagem, é preciso reconhecer que o dicionário pode ser avaliado como um dos aspectos externos que contribui para a aquisição lexical, isto é, um dos fatores que podem ser oferecidos a um aprendiz para que consiga ampliar seu léxico (LEFFA, 2000, p. 23).

Ao se pensar em situações nas quais um dicionário pode enriquecer uma aula de língua estrangeira, tem-se: a) eliminar dúvidas não somente de alunos, mas também de professores; b) auxiliar na leitura e na pronúncia (produção oral); c) ampliar vocabulário, auxiliando na produção escrita; d) refletir sobre equivalentes propostos; e) diminuir a dependência do professor.

Apesar dessas notórias ações que partem do manuseio de obras lexicográficas, percebe-se que não há uma habilidade quanto ao uso de dicionários nas instituições de ensino, o qual parece demonstrar a pouca intimidade entre docentes e essas obras, limitando, consequentemente, os benefícios desse relevante material, também de cunho educacional, como instrumento precioso no processo de ensino-aprendizagem junto ao corpo discente (HAYATI; MOHAMMADI, 2005, p. 64). 
Binon e Verlinde (2000, p. 129) acentuam que a utilização do dicionário não ocorre por si só, automaticamente, mas reforçam que o ensino da maneira como utilizá-lo deva ser uma prática presente e constante de um cronograma estruturado de ensino do léxico. Apresentam-se ainda Nesi (1999) e Nation (2002) que argumentam sobre o fato de que a utilização do dicionário por aprendizes de uma língua estrangeira compreende uma associação de habilidades interligadas que exigem exercício habitual e metódico a fim de serem coordenadas. Com efeito, nessa perspectiva, o uso da obra lexicográfica como estratégia efetiva no processo de ensino-aprendizagem de vocabulário somente será possível se os consulentes forem ensinados a percorrer, meticulosamente, esse tipo de obra.

Referindo-se aos efeitos positivos alcançados pelo uso didático dos dicionários, é possível constatar que, no Brasil, ainda há muito para se pesquisar quanto a eles. No entanto, internacionalmente, muitas são as pesquisas que corroboram a prática desenvolvida na UAMI, pelo menos, com relação à compreensão de leitura. Sob essa perspectiva dos resultados de seu uso, Welker (2006) ressalta que

no que concerne ao efeito do uso, ainda há poucos resultados conclusivos, seguros e generalizáveis; aliás, às vezes chega-se a conclusões que apenas confirmam o que parece óbvio. Em outros casos, há realmente constatações surpreendentes. No Brasil, o número de pesquisas sobre o uso do dicionário em geral é muito reduzido. Quanto ao efeito da utilização de dicionários em determinadas situações, as pesquisas já concluídas limitam-se, por enquanto, às situações compreensão de leitura (LEFFA, 1991, 2001; COURA SOBRINHO, 1998; ERNST-MARTINS, 2003) e retenção de itens lexicais (CONCEIÇÃO 2004, 2004a). Somente Coura Sobrinho e Conceição estudaram o uso de dicionários comuns, já que Leffa e Ernst-Martins verificaram o efeito de um software especial (WELKER, 2006, p. 236237).

A experiência durante o curso de 'Língua e Cultura Italianas' aponta, portanto, para a necessidade de um repensar dos currículos dos cursos de licenciatura com habilitação em línguas estrangeiras. O primeiro passo poderia ser a inserção de tópicos 
com uma visão geral da obra lexicográfica, refletindo sobre a macro e a microestrutura, a classificação tipológica dos dicionários, com isso, o futuro docente poderia explorar melhor a obra lexicográfica conforme às necessidades de seus alunos, consequentemente, eles estariam mais familiarizados com elas, potencializando seu uso como material de apoio.

Em certa medida, tanto docentes quanto discentes desconhecem os dicionários e, como resultado, deixam de usá-los em sua plenitude. É tarefa do professor indicar aos alunos como explorar ao máximo a riqueza de informações contidas nessas obras, para isso, é fundamental que sejam desenvolvidas diferentes atividades, avançando para além do significado, ortografia e pronúncia das palavras.

Também deve-se ressaltar que as contribuições da Lexicografia Pedagógica, tais como, exploração de dicionários a fim de conferir êxito no processo de ensinoaprendizagem, suas estratégias para aquisição lexical, a reflexão sobre quais são os critérios utilizados para selecionar o vocabulário, iriam enriquecer os cursos de língua estrangeira. Desse modo, os licenciandos, ao receberem uma formação que contemple um olhar mais detalhado para as diversas obras dicionarísticas, teriam como resultado uma melhor competência docente. Logo, quando esses partirem para o dia a dia em sala de aula, poderiam oferecer um novo olhar sobre esses materiais complementares a seu próprio corpo discente que os utilizará com maior apropriação.

\section{O ensino de língua italiana na UAMI}

Um dos programas universitários desenvolvimentos em Barretos é o ‘UNIFEB Aberta à Melhor Idade (UAMI)'. Esse é um projeto de extensão universitária voltado para atender a população acima de 45 anos, proveniente de cidades do interior norte e noroeste do estado de São Paulo. Além disso, é um espaço pedagógico de aperfeiçoamento profissional dos graduandos dos diversos cursos dessa instituição, tais como Serviço Social, Educação Física, Odontologia e Pedagogia, assim, aliados à 
prática, são desenvolvidas pesquisas e estudos. Com isso, realiza-se o processo de formação profissional por meio da interação ensino-pesquisa-extensão. Tal projeto visa à promoção na melhoria da qualidade de vida, bem como o aumento da autoestima e a troca de experiências das pessoas que se encontram na faixa etária mais elevada da sociedade, oferecendo atividades multidisciplinares no período vespertino.

O projeto UAMI foi implantado em 2014 e, a cada semestre, as atividades e disciplinas variam, sendo que já foram ministradas aulas de dança, alongamentos, práticas de uso de novas tecnologias e ainda aulas de línguas estrangeiras como inglês, espanhol e italiano. Esse é um projeto de cunho voluntário, portanto, os professores que ali ministram suas aulas oferecem os cursos de acordo com a disponibilidade de seu tempo e, por isso, determinados cursos são oferecidos em um semestre, mas não no seguinte. Por parte dos alunos, é paga uma taxa simbólica (no valor de $R \$ 40,00$ ), que é revertida para custear o lanche que lhes é preparado pelo UNIFEB. A logística letiva ocorre da seguinte maneira: os programas de estudos são realizados das $14 \mathrm{~h}$ às $17 \mathrm{~h}$, sendo que um curso é ministrado das $14 \mathrm{~h}$ às $15 \mathrm{~h} 15$, faz-se uma pausa de quinze minutos para o lanche, em seguida, às 15h30, inicia-se o segundo bloco de aulas.

Inicialmente, no primeiro contato, não somente em cursos de italiano, mas também para qualquer outro curso a ser ministrado, há um momento para as apresentações. Na sequência, discutem-se interesses e objetivos dos alunos com relação ao curso ao qual se dispuseram a participar. Por fim, são estabelecidos cronograma e proposta de ensino.

Nesse momento, os alunos expõem suas razões e, muito comumente, o turismo se apresenta como um dos principais motivos para se estudar a língua italiana. Mesmo aqueles que se manifestaram comentando que ainda não conheciam a Itália, também demonstraram interesse em viajar para essa terra no futuro. Vale destacar o comentário de uma viúva que compartilhou seu desejo de retornar à Itália, país onde se casou e enterrou o marido, pois desejava rever os familiares por parte de seu 
falecido esposo. Os motivos, em geral, eram (e ainda são) as viagens turísticas para a Itália, os pratos, as canções e a curiosa gesticulação tipicamente italianos. A partir dos comentários de todos os matriculados, percebia-se que, muito mais do que a língua, eles são interessados pelas questões culturais que dizem respeito ao povo.

É importante mencionar que vários alunos se interessaram por estudar a língua italiana também motivados pelos estereótipos amplamente difundidos dos quais podem ser citados os hábitos alimentares, a música, a história e a religião. Além, claro, do destaque negativo: a máfia italiana.

O segundo passo tem sido apresentar um pouco sobre a história italiana, em linhas gerais, para situar os alunos. Obviamente, não é uma tarefa simples, mas necessária para que tenham em mente a ocupação e a unificação da Itália, bem como seus desdobramentos que mantêm uma relação direta em termos, por exemplo, das várias possibilidades das escolhas lexicais.

A UAMI, enquanto projeto de extensão, tem apresentado um número de matriculados oscilante a cada semestre, mas no que se refere ao curso de italiano, há um constante aumento, pois a turma iniciada com 5 alunos (em 2016), hoje, possui cerca de 22 idosos (dados do primeiro semestre de 2018). Sendo que, desde o início, a participação deles, compartilhando suas histórias, fez-se presente e as aulas continuam se mantendo leves e descontraídas. Vale mencionar que o tempo para o aprendizado não tem se mostrado como objetivo principal desse grupo discente.

Não é adotado nenhum livro específico como material didático norteador. Essas aulas são elaboradas após uma decisão, em conjunto, sobre o(s) tema(s) que os idosos gostariam que fosse abordado. Tendo isso como ponto de partida, as aulas são apresentadas em PowerPoint, sobretudo por meio de figuras, além do uso de lousa e de materiais que estejam disponibilizados via motores de busca (por exemplo, www.google.it), pelos quais é possível assistir a vídeos que contribuem para trazer uma maior ludicidade às aulas. Vale ressaltar que essa prática é muita bem aceita por 
esses alunos, superando cada vez mais suas expectativas, conforme manifestação em sala, pois são oferecidas várias situações comunicativas como alternativas para o êxito no desenvolvimento do ensino.

É preciso demonstrar que o livro didático não é a única forma de aprendizagem e, cada vez mais, nossos alunos têm constatado o quanto o mundo tecnológico contribui para isso. Assim, pelos vídeos, percebem diferenças regionais na Itália, tais como, uma pronúncia mais aberta de vogais por um italiano do norte, enquanto um italiano do sul tende a pronunciar vogais mais fechadas - por vezes, esses alunos não conseguem ter essa percepção apenas lendo a respeito disso nos livros didáticos. Além disso, também a questão dos dialetos que, raras vezes, é abordada por esses materiais, porém, rapidamente, observada em filmes ou em canções, pois a questão do uso dialetal se diferencia da língua italiana padrão oficial e, de modo geral, é ignorada pelos materiais didáticos.

Quando são propostos exercícios orais, conforme a leitura segue, pausas são feitas e surgem questões sobre pronúncia, levantando dúvidas e opiniões acerca do texto. Também se deseja estimular a produção oral em italiano, pelo menos, de algumas palavras ou frases, entretanto, já que há alunos que não se sentem à vontade para falar em língua estrangeira, ou mesmo, não conseguem expressar o que pretenderiam usando o italiano, sempre foi permitido a utilização da língua materna para que se expressassem, dado que o propósito não é inibir ninguém, mas sim estimulá-los à oralidade na língua estrangeira.

Esses alunos sempre foram orientados para que estudassem da forma que lhes parecesse melhor, seja individualmente ou em grupo, consultando os dicionários disponíveis ou o próprio professor. A respeito disso, são disponibilizados um dicionário bilíngue impresso português-italiano [Michaelis (2009), doravante MI], um semibilíngue impresso italiano-português [Martins Fontes (2004), doravante MF], um monolíngue italiano impresso (Zingarelli, 2013) - doravante ZI - e dois dicionários 
monolíngues brasileiros eletrônicos [Aurélio (2010), doravante AU; e Houaiss (2009), doravante $\mathrm{HO}$, sendo que esses últimos são acessados pelo laptop do professor para que todos possam consultar, além de ser permitido que cada aluno idoso possa usar seu próprio dicionário.

A possibilidade de se trabalhar com uma ampla variedade temática foi, e tem sido, imprescindível para o bom andamento das aulas visto que, como não há a adoção de nenhum material didático específico, gera sempre uma expectativa pela aula seguinte por parte dos idosos. Objetiva-se proporcionar aos alunos da melhor idade a possibilidade de discutir sobre temas diversos (estereótipos italianos, cozinha italiana, arte, história, política etc.) a fim de observar suas opiniões e de estimular o desempenho deles durante o processo de ensino-aprendizagem. A variedade temática dos textos estudados corresponde ao interesse manifestado pelos próprios alunos no início do curso (em fevereiro de 2016) e que, constantemente, continuam solicitando. Com isso, já foram tratados textos variados, tais como, de caráter político-social, histórico-político, filosófico-religioso, sobre o cotidiano dos italianos etc.

Em síntese, são apresentadas, discutidas e refletidas as concepções desses alunos idosos quanto à língua e a cultura, tanto de chegada quanto de partida, bem como sobre o processo de ensino-aprendizagem. Ao serem levados em consideração os aspectos que envolvem a cultura da língua-alvo e da língua-fonte, consegue-se alertar os alunos de língua estrangeira para perceberem como a cultura é produtora de significados que ultrapassam a palavra escrita ou falada. Na sequência, é descrita essa experiência educacional de ensinar italiano para um grupo de idosos com o auxílio de dicionários.

\subsection{UAMI: contato e auxílio do dicionário em sala de aula}

Como já mencionado, este estudo se originou a partir da experiência do autor, visto que é o docente responsável por implantar e ministrar o curso de italiano na 
referida instituição educacional, desde o primeiro semestre de 2016 . O curso se pauta em difundir a cultura italiana e ensinar a língua em nível básico, com duração de duas horas semanais, durante o semestre letivo. O grupo tem se mantido e aumentado a cada ano, hoje, há mais de vinte matriculados.

Com os alunos de italiano, além do material preparado pelo professor, conforme explicitado anteriormente, são utilizados dicionários monolíngues e bilíngues a partir dos quais são propostas a explicação de siglas, abreviações, a ordem em que aparecem as unidades lexicográficas, as marcas de uso. Na prática, ao se buscar por equivalentes tradutórios nos dicionários bilíngues - neste caso, MI e MF -, por vezes, a unidade lexical em português não é entendida pelos idosos, assim, também é feito uso de dicionários brasileiros monolíngues - AU e $\mathrm{HO}$ - a fim de explicar a todos a definição estabelecida nessas obras lexicográficas. Esse trabalho proativo dos alunos é extremamente motivador, pois sempre desejam compartilhar suas descobertas com os demais colegas. A cada novo significado estudado e apreendido, seja na língua materna ou na língua estrangeira (neste caso, o italiano), eles demonstram uma sensação de vitória.

Durante os exercícios em sala, às vezes, fazem preenchimento de frases descontextualizadas, outras vezes, leem e respondem a perguntas de textos curtos (contos, notícias de jornais ou de revistas) e, constantemente, declaram que a busca por unidades lexicais desconhecidas à compreensão de um texto, tanto escrito quanto oral, contribui para compreender e ampliar o vocabulário pessoal por meio do uso do dicionário, cujo auxílio se torna eficaz para o melhor entendimento do contexto e para a produção escrita.

Ao procurarem no dicionário por uma lexia que, anteriormente, não fazia sentido, mas ao descobrirem se tratar de um falso amigo, os alunos querem compartilhá-la imediatamente. Por exemplo, casos como as lexias burro e bollo geraram 
risos ao descobrirem que seus equivalentes tradutórios para o português eram, respectivamente, nos textos em italiano, 'manteiga' e 'selo'.

Além disso, ao se depararem com as palavras anguria e cocomero (ambas têm como equivalente português 'melancia', fruta extremamente comum no Brasil), ficaram surpresos e um pouco acanhados quando, em um primeiro momento, encontraram na acepção que atestava o uso em português, com a marca de uso '(fig.)', a acepção 'tolo, pateta'. Outro exemplo encontrado durante as aulas foi alloggiare, unidade lexical cujo equivalente é 'hospedar', mas em sentido figurado significa 'agasalhar'.

Curioso também o item lexical caprone, cujo equivalente brasileiro é 'bode', mas cujo sentido figurado encontrado no MF foi 'pastrano, chambão, xamboqueiro'. Percebe-se que essas últimas são lexias que mantêm o significado ainda opaco, por isso houve a necessidade de utilizar os dicionários brasileiros AU e HO para esclarecer que se tratava de pessoa rude, grosseira, de traços deselegantes. Enquanto 'pastrano' e 'chambão' estavam presentes em HO, as três foram encontradas no AU, de maneira que 'pastrano' tinha a marca 'fig.' em AU, mas não constava marca de uso em HO; por outro lado, 'chambão' não apresentava marca de uso no AU, mas sim 'pejorativo' em $\mathrm{HO}$; por fim, 'xamboqueiro' não constava no $\mathrm{HO}$, mas sim no $\mathrm{AU}$, porém, este remete a 'chamoqueiro', cuja marca de uso é 'Bras. N. E.', que indica brasileirismo do Nordeste.

Esse último exemplo, serviu, à época, para discutir junto aos idosos sobre a importância de trabalhar o dicionário de uma perspectiva discursiva, destacando o quão frequente eles poderiam se deparar com a ideologia de seus autores. Deseja-se apresentar ao aluno não uma visão hermética dos dicionários, mas sim propor atividades em que esses sejam tomados como espaços flexíveis. Além disso, almeja-se a um deslocamento com relação à prática na qual o aluno se transforme de um leitor passivo de dicionários a um sujeito ativo. 
A inexperiência ou mesmo certa inocência no uso do dicionário pode acometer a compreensão, ou seja, a má utilização dessa ferramenta atrapalha, cria obstáculos no processo de compreensão, dado que a escolha por vocábulos indevidamente contextualizados pode levar a equívocos quanto à interpretação. Bordini e Aguiar (1993) lembram que, apesar de que palavras estejam explicadas em um dicionário, nunca exprimem um único significado quando estão inseridas em uma frase de um determinado texto. Sendo assim, a escolha por uma unidade lexicográfica presente nessas obras dicionarísticas passa por um julgamento de seu consulente, que irá optar por aquele item lexical que considerar mais apropriado, mas que pode não ser necessariamente o mais oportuno para o contexto em questão.

Em uma das aulas, os alunos receberam um texto em italiano para ler, tratavase de um evento cultural famoso na Itália - o Festival di Sanremo. A partir dele, os alunos deveriam realizar uma leitura inteiramente silenciosa e, em seguida, lê-lo em voz alta. Assim, aos poucos, foram lendo, individualmente, para que pudesse ser detectado o entendimento da fonética italiana por parte dos alunos.

Em se tratando do modo como realizam a leitura, a maioria sempre declarou desenvolver suas leituras buscando, primeiramente, uma compreensão global do texto e, em seguida, a procura pelas palavras consideradas 'difíceis e importantes' para sua compreensão. O procedimento adotado durante as aulas era entregar as atividades e, na sequência, os dicionários disponíveis para que fizessem uso durante todo o período de aula, sempre que sentissem necessidade, sendo que ainda estavam cientes de que poderiam consultar os colegas e o professor a qualquer momento.

Ao manusearem os dicionários impressos e eletrônicos, sempre confirmavam suas escolhas com o professor, ora por não entenderem as palavras em italiano (por exemplo, qual entrada deveria ser buscada), ou mesmo os equivalentes em português, ora pela falta de clareza dos dicionários utilizados (geralmente, pela ausência de contextualizações que os ajudassem a decidir). Por essas razões, eles decidiam pela 
'melhor escolha' perguntando para o colega que sentasse mais perto ou para o próprio professor.

Moreira (2009, p. 55) conclui que

o desconhecimento de um vocábulo poderá, possivelmente, ocasionar um desconforto ao aluno de língua estrangeira durante as atividades de leitura, ou seja, dificultando a compreensão do texto em análise, por exemplo. Neste caso, acreditamos que o uso do dicionário será um recurso a mais no momento de seu estudo (tanto na sala de aula quanto em casa) para diminuir as dúvidas em relação ao vocabulário e, sobretudo, mais um suporte facilitador na busca da aquisição da habilidade leitora desejada [...] Também acreditamos que um dicionário poderá dar subsídios importantes inclusive para o estudo do léxico, em seus diferentes aspectos. Este é o motivo pelo qual o dicionário pode ser particularmente de grande utilidade e, inclusive, imprescindível ao cotidiano da vida escolar do nosso aprendiz.

Também foi claramente constatada a falta de habilidade, entre os alunos da terceira idade, para manipular o dicionário e, consequentemente, como utilizar suas informações. A despeito do oferecimento do dicionário monolíngue italiano impresso (ZI), nenhum aluno o utilizou, alegando nível linguístico insuficiente para seu uso e desejo pela tradução imediata.

Bagno e Rangel (2006, p. 24) assinalam que é muito importante usar os dicionários de maneira racional e meticulosa, dado que tal prática ajudaria no desenvolvimento de uma "proficiência específica para a busca, o processamento e a compreensão das informações lexicográficas", um modo eficaz para desenvolver a competência leitora.

É nítida e habitual a preocupação excessiva com a tradução literal, palavra por palavra, que não necessariamente levará à compreensão do texto, ao contrário, tende a prejudicar o desenvolvimento da leitura, transformando o texto em uma lista de palavras esvaziadas de sentido. 


\subsection{Atividades desenvolvidas junto aos alunos da 'melhor idade'}

A intenção tem sido promover o ensino de língua italiana por meio de atividades que possam motivá-los e fazer com que esses alunos apresentem um postura ativa no processo de ensino-aprendizagem. Tendo essa perspectiva como norteadora, foram propostas e realizadas várias atividades, dentre elas, serão mencionadas algumas a seguir:

\subsubsection{Utilizando provérbios}

Nesse processo de ensino-aprendizagem, os exercícios envolvendo os provérbios se revelaram uma estratégia eficiente e interativa, pois eles refletem inúmeros aspectos da cultura de um povo. Dessa perspectiva, foram utilizadas diversas propostas de Roque e Sabino (2008) para explorar seu reconhecimento por parte dos alunos, como por exemplo:

(I). Ricomponi il proverbio: cada aluno idoso recebia uma cartela contendo um provérbio italiano com as palavras misturadas, fora da ordem original. Eles tentavam adivinhar o provérbio e, a cada acerto, era estabelecido um ponto. A partir desse jogo, questões linguísticas e culturais eram discutidas;

(II). Gioco della memoria: eram confeccionados provérbios italianos em folhas de papel, recortados, colocados de cabeça para baixo e os alunos precisavam encontrar o mesmo provérbio, assim, havia a intenção de fazer com que eles memorizassem aquilo que estavam lendo;

(III). Abbina i proverbi: eram oferecidos os provérbios e suas respectivas equivalências tradutórias para idosos diferentes e era solicitado que encontrassem os pares, promovendo dinamicidade e interação durante a aula;

(IV). Proverbi, pronuncia e definizioni: unidades lexicais eram recortadas de provérbios e entregues para os alunos, um deles, por vez, lia aquela que tinha à mão e, em seguida, 
os colegas precisavam descobrir a qual provérbio pertencia, com isso era discutida a pronúncia de todos e sempre se partia para a leitura de sua definição, no ZI.

\subsubsection{Envolvendo expressões com nomes ou partes do corpo de animais}

Em se tratando dos animais e suas partes, com base em Zavaglia (2010), foi formulada uma série de exercícios, um exemplo se refere a:

(V). Indovinate l'animale: cada aluno idoso recebia uma cartela contendo uma expressão idiomática italiana que se referia a animais. Eles precisavam procurar nos dicionários e descobrir qual era o animal e, então, propor uma tradução em português. Assim, verificava-se se havia correspondência cultural ou não ao mesmo animal.

\subsubsection{Envolvendo 'o colorido da linguagem'}

Ainda com base em Zavaglia (2010), também foram constituídas atividades envolvendo as cores e as diferenças de perspectiva entre o português e o italiano, sendo que os dicionários serviram para apontá-las durante o jogo Abbina i colori, comentado a seguir:

(VI). Abbina i colori: eram distribuídas as cores em italiano, sempre acompanhadas por substantivos e, em seguida, eram procurados os equivalentes em português. Na maioria das vezes, somente eram encontrados no MF, então, comparavam como os dois sistemas linguísticos (português e italiano) compreendiam as cores. Por exemplo, em italiano, nero apresenta uma conotação negativa, como verificado em lavoro nero, cuja noção se refere a algo ilegítimo e sua tradução seria 'trabalho clandestino', enquanto que, em português, 'preto' e 'negro' são utilizados indistintamente como em 'nuvens negras ou pretas anunciavam a tempestade' (ZAVAGLIA, 2010, p. 62); o rosso ('vermelho') é muito representativo na Itália para se referir a acontecimentos e fatos históricos, já no Brasil, não há tal referência registrada pelos dicionários; o giallo ('amarelo') corresponde, dentre outros aspectos, aos romances policiais italianos, já no 
português, encontra-se a expressão 'estar amarelo de' que se refere a 'estar cansado de fazer algo' (sentido ausente no italiano).

\subsubsection{Envolvendo numerais e jogos populares}

A fim de ensinar a conceituação de número, três autores - Silva, Silva e Correia (2016) - apontam para o fato de que muitos docentes utilizam, como instrumentais, objetos ostensivos (sons, grafismos, gestos) e não-ostensivos (materiais que não são manipulados por serem dotados de característica não material, tais como, as ideias e os conceitos), cuja Teoria Antropológica do Didático (TAD) considera como base (presente em toda atividade matemática). Quer dizer, para ensinar números, também em língua estrangeira, as justificativas se fazem presentes em torno de seu uso cotidiano, nos mais variados contextos. Por isso, foi proposta La Tombola.

(VII). La Tombola: para o desenvolvimento dessa atividade, eram oferecidas cartelas numeradas como aquelas próprias de bingo (tombola, em italiano). Na sequência, eram dadas vinte palavras italianas diferentes (sempre substantivos numerados) que tivessem sido estudadas na aula anterior, já sendo, portanto, conhecidas e que pudessem ser identificadas pelo aluno idoso. Todas elas estavam representadas em cartões numerados. É um exercício bastante interativo porque, com a ajuda do professor, esses discentes precisavam se lembrar do significado de cada uma delas e tentar traduzi-las sob forma de desenho na lousa, então, quem adivinhasse marcaria o número do desenho na cartela e se dirigiria até o quadro branco e, um por vez, todos os outros iam tentando adivinhar. Aquele que acertasse iria 'cantar a pedra' (pronunciar o número em voz alta, aleatoriamente) seguinte, assim, a cada acerto, era preenchida uma casella ('casinha' numerada da cartela). Não havia perdedores porque o jogo só terminava quando todos tivessem preenchido suas cartelas, de modo tal que uns precisavam ajudar os outros a completarem suas cartelas. 
Outro exercício em que os números poderiam ser retomados foi Quante sono le parole?.

(VIII). Quante sono le parole?: uma outra forma de exercício para contribuir ao reconhecimento do número de palavras usadas em uma frase corresponde ao uso de trechos de canções ou de poemas. Nessa atividade, eram lidos os versos e, então, era perguntado aos alunos quantas palavras tinham sido ouvidas por eles. Assim, permitia-se que desenvolvessem a habilidade de reconhecer a totalidade da frase para entender cada palavra que a compunha. Propicia-se uma abordagem sobre vários aspectos, tanto fonológicos quanto semântico e morfossintático.

\subsubsection{Foco nas letras, sílabas e palavras}

$\mathrm{O}$ andamento dessas próximas atividades era, à primeira vista, um reforço à apreensão do vocabulário estudado durante a aula, entretanto, era também um exercício para familiarizar os alunos com a escrita italiana.

(IX). Scopri la lettera che manca: escolhiam-se alguns trechos de poemas de autores italianos, que apresentassem rimas, então, ora as últimas vogais das palavras eram apagadas, ora eram retiradas as primeiras letras que iniciavam os versos. Com isso, eles conseguiam exercitar a memória e observar qual a pronúncia necessária para a língua italiana, pois os versos eram lidos pelo professor para que tivessem a possibilidade de preencher os espaços em branco com as respectivas letras ausentes. (X). La risposta è sì o no?: tratava-se de uma atividade que visava à compreensão textual por parte dos idosos. Esse exercício partia da escolha de uma canção, a qual os alunos iriam ouvir uma primeira vez e, em seguida, era entregue a letra com algumas lacunas a serem preenchidas. Assim, nesses espaços, colocavam-se ilustrações dos vocábulos que faltavam. Eles - os vocábulos - não deviam ser traduzidos porque os alunos precisavam ouvi-los, escrevê-los e, consequentemente, descobrir a lexia em italiano, que seria, posteriormente, 
confirmada pelo docente. Conforme tentavam adivinhar, também perguntavam ao professor se a palavra que tinham ouvido era a mesma que estavam pronunciando e escrevendo. É um exercício que tem como intenção incentivá-los a pensar no significante e no significado dessas palavras.

(XI). Ripeti, per piacere!: Ao estudarem uma determinada canção, um dos exercícios propostos correspondia às repetições sob a forma de coro, já em outros momentos, sob a forma individual e/ou de jograis. Geralmente, escolhiam-se os refrões para serem estudadas a pronúncia e a entonação de frases. Com o passar do tempo, o ritmo dos alunos também ia se aprimorando.

(XII). Il telefono senza filo: como todos os alunos possuíam celulares com o aplicativo whataspp, era realizado um exercício que consistia em escolher um aluno para dar início a uma história, de preferência curta e em língua italiana. Esse escolhido saía da sala e enviava uma mensagem de áudio para um colega de turma que, por sua vez, deveria ouvir a mensagem, sair da sala e dar sequência àquela história, enviando-a, por áudio, a outro colega e, assim, sucessivamente, até que todos os idosos tivessem participado e acrescido uma parte à história contada em grupo. Quando as palavras permaneciam em português, o professor as traduzia e as escrevia na lousa, chamando a atenção para a correção e autocorreção deles.

No decorrer de todos esses exercícios propostos, eles procuravam observar onde estava a tônica silábica, primeiramente, via confirmação no dicionário MF, pois, nessa obra dicionarística, as unidades lexicográficas não oxítonas são evidenciadas: (i) pela indicação da vogal tônica sublinhada; (ii) pela indicação de abertura (sublinhado) ou fechamento (ponto subscrito) da vogais tônicas 'e' e 'o'. Em um segundo momento, pronunciavam-nas ao professor com o intuito de obter sua confirmação. 


\subsubsection{Voltando-se para a pronúncia italiana}

Conforme destacam Fulgêncio e Bastianetto (1993), indivíduos nativos de língua portuguesa, ao falarem em italiano, apresentam dificuldades que se relacionam à pronúncia de vários fonemas, tais como, ' $\mathrm{M}^{\prime} \mathrm{e}$ ' $\mathrm{N}$ ' que, em português, são nasais, já em italiano são orais. Outro aspecto linguístico da oralidade italiana diz respeito às consoantes dobradas (le doppie), visto que, em italiano, encontramse palavras com significados diferentes que são grafadas pela dobra de consoantes, será a pronúncia mais alongada que estabelecerá essa dobra.

Além disso, é importante lembrar que, no italiano, a pronúncia do ' $R$ ' é maiormente (dado que, no Vêneto, por exemplo, tende a ser retroflexo) vibrante (como em 'fora', 'caro' e/ou 'prato' do português brasileiro), o 'L' é pronunciado como 'L', mesmo em final de palavra e/ou sílaba, assim, nunca se apresenta como uma vogal ' $U$ ' (fenômeno característico na fala de brasileiros) e ainda, por fim, 'GN' e 'GLI' equivalem, respectivamente, à pronúncia em português de ' $\mathrm{NH}^{\prime}$ e 'LH'. Essas são particularidades que merecem destaque em aulas de ensino de italiano e que precisam ser exercitadas constantemente para o aprimoramento do processo de aprendizagem dessa língua estrangeira, pois as diferenças entre essas duas línguas pode causar dificuldades para os lusófonos.

Desejando conscientizar o corpo discente sobre essas questões fonéticas, que podem causar dificuldades linguísticas no aprendizado, foram apresentados textos específicos para cada uma das situações supramencionadas, como por exemplo:

(XII). Attenzione alla 'GN': é um exercício que oferece um texto pequeno, sob a forma de poema, cujo objetivo é treinar a pronúncia do dígrafo 'GN'. Cada um dos alunos devia ler o texto a seguir (JOP, 2018, on-line), individualmente:

"Vedo un ragno nel suo regno, che lavora con impegno; e uno gnomo che fa il bagno 
con un cigno nello stagno."

(XIII). Attenzione alla 'GLI': também é um exercício que oferece versos que rimem, buscando, da mesma forma que a atividade anterior, treinar a pronúncia, neste caso, do dígrafo 'GLI'. Da mesma maneira, cada um dos alunos o lia (JOP, 2018, on-line), individualmente:
“Quando il coniglio
Senza consiglio
Con la coniglia
Fece famiglia
Gli nacque un figlio
E poi una figlia,
Poi un altro figlio
E un'altra figlia.
Ora il coniglio
Senza consiglio
Ha una famiglia
Lunga tre miglia."

(XIV). Attenzione alla 'Z': para estudar a pronúncia do 'Z', foi utilizado, por exemplo, o seguinte texto (JOP, 2018, on-line):
“Nel castello di Mister Pazzino de' Pazzi
C'era una pazza che lavava
Una pezza di pizzo nel pozzo.
Mister Pazzino de' Pazzi diede
Una pizza alla pazza che lavava
La pezza di pizzo nel pozzo.
La pazza rifiutò la pizza,
così Mister Pazzino de' Pazzi buttò
la pazza, la pizza e la pezza nel pozzo
del castello di Mister Pazzino de' Pazzi."

$(\mathrm{XV})$. Come si pronuncia 'QU'?: para estudar a pronúncia do 'QU', fez-se uso, por exemplo, do seguinte texto (JOP, 2018, on-line):

“C'è il questore in questura a quest'ora? 
No. Non c'è il questore in questura quest'ora; perché se il questore fosse in questura quest'ora sarebbe questa la questura."

As atividades para progredir na recepção e na pronúncia dos fonemas são muito variáveis, por isso devem ser utilizadas de modo gradual conforme o nível linguístico dos alunos. Para tanto, nesse momento, os dicionários foram muito utilizados para esclarecer vários significados das unidades lexicais, observando-se que uma eventual tradução dos versos supracitados não recuperaria, em sua totalidade, os elementos fonéticos que foram alvos de estudo. Um outro modo para sanar as dificuldades fonético-fonológicas é por meio da leitura, em classe, de poesias.

\subsubsection{Passando-se da oralidade para a escrita}

Quando se percebe que os alunos idosos precisam de um incentivo maior para produzir algo, seja produção oral ou escrita, são estimulados alguns tipos de exercícios específicos para tal fim, como por exemplo:

(XVI). Facciamo una filastrocca?: Dependendo do tema trabalhado em aula e, consequentemente, do volume de vocabulário estudado, propunha-se que os alunos criassem, em grupos, suas próprias parlendas - gênero textual que consiste em rimas infantis utilizadas em brincadeiras, podendo contribuir como uma técnica de memorização - a fim de que pudessem aprimorar a fonética italiana e que adquirissem mais vocabulário. A confirmação da palavra escrita vinha por meio da checagem junto aos dicionários utilizados para auxiliar essa atividade.

Tendo em vista outras possibilidades de se trabalhar em classe com parlendas, ainda foi aplicada a atividade de encontrar o 'intruso':

(XVII). Trova l'intruso dentro la filastrocca: desejava-se que o aluno refletisse sobre o mecanismo para se constituir esse gênero, quer dizer, que ele pudesse perceber a construção de rimas que devia estar presente. Foi oferecida uma parlenda pronta 
para cada grupo, previamente separado; na sequência, precisavam reconhecer qual era o vocábulo 'intruso', isto é, aquele que devia ser retirado porque não produzia a rima esperada. Todos os grupos precisavam ajudar uns aos outros a fim de que todos os 'intrusos' fossem descobertos.

\subsubsection{O desafio da tradução}

Ao se confrontarem os dois sistemas linguísticos, uma atividade prática, como a tradução, foi muito bem aceita pelos discentes por meio de dinâmicas como a descrita abaixo:

(XVII). Come si dice in portoghese?: divididos em grupos, cada equipe propunha uma 'frase-desafio', em português, para a outra equipe que precisava vertê-la para a o italiano. Era observado, além da pronúncia, o nível de intimidade no manuseio do dicionário e o nível linguístico em que os estudantes se encontravam. Foram realizadas várias rodadas de 'frases-desafio' durante os últimos quarenta minutos das aulas do dia.

Para um bom desempenho nesse exercício, a maior familiaridade com dicionários ajudou aqueles que percorriam e desbravavam melhor essa obra. Em meio a diferentes materiais dicionarísticos entre os grupos, havia um certo rodízio para que todos pudessem fazer uso da quantidade e variedade disponíveis.

É preciso sempre destacar que a compreensão é, de fato, um processo particular, envolvendo inúmeros fatores inter-relacionados, tais como, domínio do código linguístico, variadas habilidades cognitivas, além de um amplo (re)conhecimento de mundo. Assim, em grande medida, as pistas extralinguísticas, das quais os idosos dispõem, desempenham um papel fundamental para a compreensão e, consequentemente, para a tradução e/ou versão, portanto, podem preencher eventuais lacunas causadas pelo (re)conhecimento imperfeito do código linguístico. 
Por isso, faz-se necessário a contextualização semântico-pragmática de todos os exercícios que venham a ser desenvolvidos em aula. Logo, é necessário que as atividades, sobretudo aquelas que envolvem texto escrito, estejam contextualizadas, assim como sustenta Coracini (2005, p. 25), "não se trata mais de perseguir a unidade ilusória do texto, mas de amarrotá-lo, recortá-lo, pulverizá-lo, distribuí-lo segundo critérios que ultrapassam ao nosso consciente, critérios construídos por nossa subjetividade".

Portanto, não é o objetivo deste artigo e por isso esta questão não será aprofundada, mas vale mencionar que se deve evitar a tradução literal, pois, na maioria das vezes, ela tende a banalizar o processo de ensino-aprendizagem, visto que reduz a apenas o estudo da gramática normativa e restringe os possíveis significados de determinada lexia.

\subsubsection{Estimulando os alunos idosos para que pensem no italiano fuoriclasse}

Atividades fora da sala de aula, mas em outros ambientes do centro universitário também foram proporcionadas a esses alunos, tal como Fuoriclasse. (XVIII). Fuoriclasse: trata-se de uma atividade ao ar livre. Os estudantes eram levados para dar um passeio pelo câmpus, sendo que o intuito era de conversar em italiano e descobrir um novo vocabulário que os rodeasse. Com isso, foi proporcionada a eles uma didática interdisciplinar experimental. As várias dúvidas que surgiram durante esse ambiente externo foram, posteriormente, esclarecidas na lousa em aula.

\subsubsection{Elaborando um cruciverba}

As palavras cruzadas (cruciverba, em italiano) correspondem a um passatempo muito difundido no Brasil. Foi estabelecido que, a partir do conjunto de novas palavras aprendidas durante um mês de aulas, os alunos deveriam produzir suas próprias cruzadinhas (assim, popularmente conhecidas) e, então, foram trocadas entre os 
colegas de sala para que resolvessem o preenchimento e obtivessem as palavras inteiramente escritas.

(XIX). Cruciverba: primeiramente, estabeleceu-se um tema que tinha sido estudado, assim, conforme as dúvidas de escrita iam surgindo, o professor explicava e relembrava-lhes a forma de escrever, a partir disso, eles montavam cada cruciverba da maneira como desejassem.

\subsubsection{Localizando a Itália e suas cidades no mapa mundi}

Procurou-se estabelecer uma interdisciplinaridade da língua italiana com várias áreas do saber, como por exemplo, a geografia, a partir da qual foram oferecidos dois exercícios:

(XX). Mappa del mondo: quando ocorria um fato de destaque em solo italiano, sempre, trazia-se um mapa para sala de aula e o exercício era de localizar onde havia ocorrido aquele determinado acontecimento. Antes disso, eram entregues mapas com as regiões recortadas para que os estudantes, em grupos de 3 ou 4, pudessem montar o mapa político italiano, somente a partir dessa montagem, passava-se a discutir algum evento, presente ou passado, nesse país europeu;

(XXI). I cantanti in Italia: outra atividade com uso de mapas se deu conjugando cidades e cantores italianos. Também em equipes, cada um dos membros desses grupos recebia um nome de um cantor, juntamente com o nome de sua cidade natal e algumas informações geográficas (relevo, clima, vegetação, pontos cardeais etc.). Era preciso que os alunos descobrissem as localidades de origem de cada cantante.

Em todas essas atividades mencionadas, os alunos da 'melhor idade' demonstraram interesse em sua realização e solicitaram que fossem repetidas as mesmas em outros dias de aula, pois, na visão de todos, contribuíram para o ensino do italiano. Além disso, também insistiram para que a proposta de uso de dicionário 
continuasse a ser adotada, pois trouxe um novo olhar para seu uso e aproveitamento em sala.

Curiosamente, a aluna mais velha, de 84 anos, tinha mais intimidade com os nomes de animais e de cores, por isso obteve maior êxito nessas atividades, enquanto que os mais 'jovens', entre 45 e 55 anos, obtiveram maior êxito nas atividades relacionadas aos provérbios.

Essas atividades foram desenvolvidas ora em grupo, ora individualmente, entretanto, em ambas situações, os idosos sempre demonstraram entusiasmo, espontaneidade e motivação.

\section{6. À guisa de conclusão}

Não há dúvidas de que ensinar é um desafio cotidiano, por conseguinte, ensinar alunos idosos não se apresenta como uma exceção a essa afirmativa. Em decorrência dos vários anos de vida desses estudantes, eles mesmos possuem vários modelos de ensino e de professores pelos quais já experienciaram várias abordagens pedagógicas e diversos tipos de materiais, assim, muitas comparações são feitas e paradigmas podem ou não serem obstáculos ao processo de ensino-aprendizagem.

Nesse processo, faz-se necessário que o docente esteja atento para desconstruir estereótipos culturais e contribuir para o aprendizado da língua estrangeira. Por isso, no que se refere ao relacionamento entre o professor e o aluno idoso, é preciso que o docente motive esse discente a fim de desenvolver seu aprendizado.

A leitura não deve permanecer presa à literalidade, mas tomada de modo polissêmico, de maneira a advertir os alunos idosos e prepará-los para as formas lexicais que serão encontradas fora dos espaços escolares. Além disso, a utilização do dicionário serve como aporte para o deslocamento de práticas nas quais a leitura seja extração de um sentido estabilizado no verbete apresentado, pois é um tipo de obra que pode ser tomada em seus aspectos linguísticos, políticos, sociais, culturais, 
históricos ao registrar como o léxico, ao longo do tempo, transforma-se ou se mantém, trazendo à tona outros e novos sentidos.

Por fim, neste relato, transcorrem alguns momentos vivenciados pelo autor durante esses quase três anos de ensino da língua italiana para alunos com idade superior a 45 anos, discorrendo sobre variadas temáticas e também apontando para atividades cujos resultados foram positivamente relevantes. Além disso, todas as aulas sempre têm sido enriquecidas pela contribuição calorosa desses alunos, que participam, interagem, pensam e refletem sobre a língua, principalmente, por meio do uso dos dicionários. Valores e concepções têm se modificado ao longo do tempo, um trabalho extremamente gratificante e enriquecedor, que é reconhecido por seu valor e relevância no cenário brasileiro contemporâneo.

A 'melhor idade' compreende a parcela da sociedade que ainda permanece ignorada por muitas instituições nacionais, entretanto, neste início de século, tem sido visto um aumento de cursos voltados para esse público específico. Eles vêm se espalhando também graças à divulgação não somente da mídia, mas principalmente dos trabalhos científicos desenvolvidos a seu respeito que vêm propiciando ótimos resultados junto aos idosos.

Já na introdução deste artigo, foi comentado sobre as recentes estatísticas que apontam para o maior número de pessoas mais velhas vivendo no Brasil, reforçando a necessidade de serem pensadas atividades que lhes interessem enquanto cidadãos ativos. Ressalta-se ainda que a bibliografia referente ao processo de ensinoaprendizagem não se mostra tão abundante se comparada àquela que se volta ao público mais jovem, por isso é necessário buscá-la em outras áreas, tais como, na educação e na sociologia. Em um primeiro momento, a pouca literatura acerca do ensino na terceira idade parece ser algo curioso e estranho, tendo em vista que o mundo é majoritariamente controlado por pessoas que pertencem a essa faixa etária. O escopo deste estudo não se trata de levantar questões sócio-político-econômicas com 
relação aos idosos, apenas se limita a relatar uma experiência de docência envolvendo a língua italiana.

Essa é uma experiência de quatro semestres letivos de observação e de coleta de dados durante a construção desse processo de ensino-aprendizagem de língua italiana como língua estrangeira. A tendência dos alunos era (e é) a de responder ora em italiano (para frases bem curtas) ora em português (para resposta mais longas), porém, gradativamente, revelam um maior potencial comunicativo na língua-alvo.

Em todo início de semestre, há um questionário que é entregue para que eles preencham com suas expectativas e desejos de temáticas relacionadas ao universo italiano, bem como a uma autoavaliação de seus conhecimentos quanto a essa língua. Partindo desse ponto, são traçados exercícios, atividades, além de diversas revisões de vocabulário e de estrutura da língua.

Com efeito, há uma imensa gama de possibilidades de pesquisa junto aos idosos de modo que a Pedagogia Lexicográfica pode contribuir partindo de sua perspectiva de ensino por meio das obras lexicográficas, por exemplo, para entender como o léxico tem se desenvolvido diante do momento sócio-histórico-cultural vivenciado pela sua sociedade.

Portanto, poderia ser sugerido, aos futuros pesquisadores, que tenham um olhar mais detalhado para as estratégias de ensino das línguas estrangeiras para esse público-alvo, pois cada uma apresenta particularidades muito distintas. Por exemplo, é raro encontrar materiais didáticos que tratem da questão da aposentadoria, da nostalgia, quer dizer, temáticas que interessam a esses alunos idosos, mas que não são encontradas nos livros didáticos e, quando o são, aparecem superficialmente.

\section{Referências bibliográficas}

ALMEIDA FILHO, J. C. P. Dimensões comunicativas no ensino de línguas. Campinas: Pontes, 1993. 
BAGNO, M.; RANGEL, E. O. Dicionários em sala de aula. Brasília: Ministério da Educação, Secretaria de Educação Básica, 2006. 155 p.

BENEDETTI, I. C. Dicionário Martins Fontes Italiano-Português. São Paulo: Martins Fontes, 2004.

BIDERMAN, M. T. C. O dicionário padrão da língua. Alfa. São Paulo: UNESP, v. 28 (supl.), p. 27-43, 1984.

BINON, J; VERLINDE, S. A contribuição da lexicografia pedagógica à aprendizagem e ao ensino de uma língua estrangeira ou segunda. In: LEFFA, V. J. (org.). As palavras e sua companhia: o léxico na aprendizagem de línguas. Pelotas: Educat, 2000. p. 93118

BORDINI, M. G.; AGUIAR, V. T. Literatura: a formação do leitor (alternativas metodológicas). 2. ed. Porto Alegre: Mercado Aberto, 1993.

CORACINI, M. J. Concepções de leitura na (pós)-modernidade. In: LIMA, R. C. C. P. (org). Leituras: múltiplos olhares. Campinas, SP: Mercado de Letras, S. J. da Boa Vista, SP: Unifeob, 2005.

DEBRAY, M. Débats Parlementaires. In: Journal Officiel de la République Française, v. 11, p. 593, 1961. Disponível em: http://archives.assemblee-nationale.fr/1/cri/19601961-droit/003.pdf. Acesso em: 19 out. 2018.

FERREIRA, A. B. H. Novo Dicionário Eletrônico Aurélio versão 7.0. 5. ed. Curitiba: Editora Positivo Informática LTDA, 2010.

FRIEDAN, B. The fountain of age. New York: Simon \& Schuster, 1993.

FULGÊNCIO L.; BASTIANETTO P. In Italiano: Manual de Gramática Contrastiva para falantes de português. Perugia: Guerra Edizioni, 1993.

HADDAD, E. G. M. A ideologia da velhice. São Paulo: Cortez, 1986.

HALL, G. Exploring English Language Teaching: Language in Action. New York: Routledge, 2011. DOI: https://doi.org/10.4324/9780203827840

HAYATI, A. M; MOHAMMADI, M. P. A comparative study of using bilingual and monolingual dictionaries in reading comprehension of intermediate level. The Reading Matrix, [s. 1.], v. 5, n. 2, sept. 2005. Disponível em: http://www.readingmatrix.com.articles. Acesso em: 25 mar. 2018. 
HOUAISS, A. Dicionário Eletrônico Houaiss da Língua Portuguesa versão 1.0. Editora Objetiva, 2009.

INSTITUTO BRASILEIRO DE GEOGRAFIA E ESTATÍSTICA. IBGE. Projeção da população do Brasil por sexo e idade para o período de 1980-2050. Revisão. Rio de Janeiro, 2004.

JOP. Filastrocca della gn. FattoreMamma Network, Milano, 15 março 2018. Disponível em https://www.filastrocche.it/contenuti/filastrocca-della-gn/. Acesso em: 15 nov. 2018.

JOP. La pazza. FattoreMamma Network, Milano, 15 março 2018. Disponível em: https://www.filastrocche.it/contenuti/scioglilingua-0017-4/. Acesso em: 15 nov. 2018.

JOP. Scioglilingua. FattoreMamma Network, Milano, 15 março 2018. Disponível em: https://www.filastrocche.it/nostalgici/scioglil/s 15.htm. Acesso em: 15 nov. 2018.

LEFFA, V. J. (org.). As palavras e sua companhia: o léxico na aprendizagem de línguas. Pelotas: Educat, 2000.

MOREIRA, G. L. O uso do dicionário monolíngue na sala de aula: uma ferramenta para compreensão leitora em língua espanhola por alunos avançados de espanhol/le. 2009, 229 f. Dissertação (Mestrado em Linguística Aplicada). Centro de Humanidades, Universidade Estadual do Ceará, Fortaleza, 2009.

NATION, I. S. P. Learning vocabulary in another language. 3. ed. UK: Cambridge, 2002.

NESI, H. The specification of dictionary reference skills in higher education. In: HARTMANN, R. R. K. (ed.) Thematic Network Projects. Subproject 9 - Dictionaries - Dictionaries in Language Learning, Final Report Year Three, p. 53-67, 1999. Disponível em: http://www.web.fu-berlin.de/elc/tnp1/SP9dossier.pdf. Acesso em: 20 fev. 2018.

PEREIRA, E. T. O idoso e o aprendizado de uma nova língua: o descortinar de trocas sociais e afetivas. 2005. 207 f. Dissertação. (Mestrado em Gerontologia Social). Programa de Estudos Pós-Graduados em Gerontologia Social. Pontifícia Universidade Católica de São Paulo, São Paulo. 2005.

PIUMINI, R. Coniglio senza consiglio. Parole in gioco, Roma, 13 agosto 2010. Disponível em: https://paroleingioco.wordpress.com/2010/08/13/coniglio-senza-consiglio/. Acesso em: 15 nov. 2018. 
POLITO, A. G. Michaelis dicionário escolar italiano: italiano-português, portuguêsitaliano. 2. ed. São Paulo: Editora Melhoramentos, 2009.

ROQUE, A. S. S.; SABINO, M. A. Mil e uma maneiras de aprender provérbios italianos com jogos e atividades. São José do Rio Preto/SP: IBILCE-UNESP, 2008. $124 \mathrm{p}$.

SCHLEPPEGRELL, M. The Older Language Learner. Washington, D.C.: ERIC Clearinghouse on Language and Linguistics. 1987. Disponível em: http://files.eric.ed.gov/fulltext/ED287313.pdf. Acesso em: 25 mar. 2018.

SCHÜTZ, R. Motivação e desmotivação no aprendizado de línguas. English Made in Brazil. 2014. Disponível em: http://www.sk.com.br/sk-motiv.html. Acesso em: 25 mar. 2018.

SILVA, V. R. R.; SILVA, I. M.; CORREIA, G. A. M. Estudos epistemológicos sobre a ideia de número no contexto dos anos iniciais do Ensino Fundamental. In: I Simpósio LatinoAmericano de Didática da Matemática, 2016. Bonito. Anais do I Simpósio Latino-Americano de Didática da Matemática. Campo Grande, MS: UFMS, 2016, p. 1-15. Disponível em: http://ladima.tuseon.com.br/uploads/file manager/source/d7322ed717dedf1eb4e6e52a37ea7b cd/Trabalhos/ITAMAR\%20MIRANDA\%20DA\%20SILVA.pdf. Acesso em: 15 nov. 2018.

VINTRÓ DE DEUS, N. A. Adulto: aluno infiel ou incompreendido? Aspectos lingüísticos, sociais e afetivos que permeiam o ensino da língua inglesa (LE) para adultos. 2007. 170 f. Dissertação (Mestrado em Linguística Aplicada). Instituto de Letras, Universidade de Brasília, UnB, Brasília, 2007.

WELKER, H. A. Pesquisando o uso de dicionários. Revista Linguagem \& Ensino, v. 9, n. 2, p. 223-243, jul./dez. 2006.

ZAVAGLIA, C. Xeretando a linguagem em italiano. 1. ed. Barueri: Disal Editora, 2010. v. 1. 128p.

ZINGARELLI, N. Vocabolario della Lingua Italiana. 12. ed. Bologna: Zanichelli, 2013. 